\title{
NUMERICAL STUDY ON THE DYNAMIC RESPONSE OF A CONCRETE FILLED STEEL TUBULAR LONG COLUMN UNDER AXIAL IMPACT BY A RIGID-BODY ${ }^{1}$
}

\author{
Han Qi, Shuohui Chen \\ Beijing No. 3 Construction Engineering Co., Ltd., China \\ JIANLEI ZOU \\ Beijing Mechanized Construction Group Co., Ltd, Beijing, China \\ Huidi Zhang, Mengsha Liu, Jinsan Ju \\ China Agricultural University, Department of Civil Engineering, Beijing, China \\ XIUXING SANG \\ Beijing Construction Engineering Group Co., Ltd, Beijing, China \\ e-mail:37329973@qq.com
}

\begin{abstract}
In this study, refined finite element models of concrete filled steel tubular long columns with length diameter ratio $(L / D)$ of 50 were established, and their dynamic responses under a rigid-body impact were explored. It is found that the form of impact load is only related to and can be predicted from the impact velocity of the rigid-body. The change of axial stress and strain with time is synchronous with that of the impact load. Furthermore, the variation characteristics of axial stress and strain with time are mainly related to the initial velocity of the rigid-body.
\end{abstract}

Keywords: concrete filled steel tubular long column, rigid-body, impact load, dynamic response

\section{Introduction}

Concrete filled steel tubular columns have been widely used in the design of important structures such as high-rise buildings and long-span bridges for its high strength, good ductility, convenience in construction, and so on. During the service period, if concrete filled steel tubular columns are subjected to unexpected loads such as explosion, impact, and collision, local component instability may occur, threatening the safety of the whole structure. However, the research on the impact resistance of concrete filled steel tubular members is still in its infancy, which mainly focuses on two types: lateral impact (Aghdamy et al., 2015; Demartino et al., 2017; Wang et al., 2019; Yang et al., 2020) and axial impact.

Among them, the research on dynamic performance of a member under an axial impact is divided into short and long columns. In terms of the impact resistance of concrete filled steel tubular short columns, Mirmomeni et al. (2017), Li et al. (2006), Zhang and Xu (2009), Prichard and Perry (2000) experimented on short concrete columns with different wall thicknesses under the axial impact by a drop weight test. In terms of the impact resistance of concrete filled steel tubular long columns, Wang (2017) established the three-dimensional axisymmetric elastic dynamic equilibrium equation of the hollow thick-walled cylindrical shell under the axial impact and studied boundary conditions of coordinated motion on the interface between the steel tube

\footnotetext{
${ }^{1}$ Presented paper from the 4th International Conference on Material Strength and Applied Mechanics, MSAM 2021
} 
and the concrete. Then, the wave velocity of the concrete filled steel tubular pile and analytical solutions of the interaction shear stress on the interface were obtained. A three-dimensional wave equation for thin-wall large-diameter concrete filled steel tubular piles was given by Liu and Ding $(2007,2008)$, and the analytical solution of this equation was obtained by using the separation of variables and the constant variation method.

In conclusion, the axial impact test of concrete filled steel tubular long columns is hardly carried out due to the limitation of test conditions, and it is challenging to study the impact resistance of the concrete filled steel tubular long column. The existing research on mechanical properties of a concrete filled steel tubular column under the axial impact mainly focuses on short columns.

This paper will study the dynamic response of a concrete filled steel tubular long column under a rigid-body impact by a numerical simulation method from characteristics of the impact load as well as the variation law of axial stress and strain. The fruits will offer some guidance for the impact resistance of members in design.

\section{Establishment of the finite element model}

\subsection{Constitutive relationship of steel and concrete}

\subsubsection{Constitutive model of steel}

It is assumed that the steel tube material adopts a bilinear plastic strain hardening constitutive model, as shown in Fig. 1.

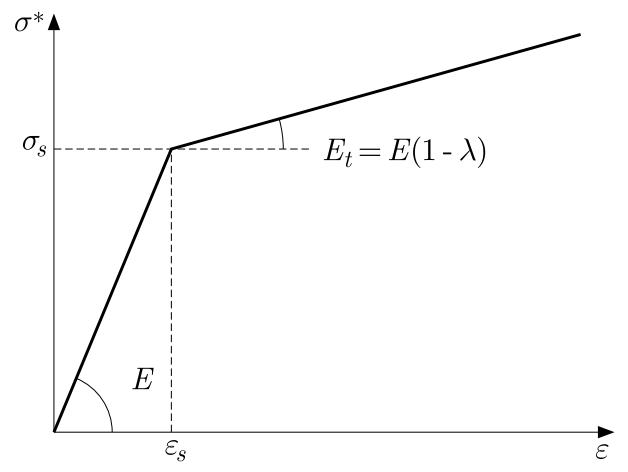

Fig. 1. Elastic-plastic constitutive model of the material

\subsubsection{Constitutive model of concrete}

In this study, the plastic damage constitutive model of concrete in ABAQUS is used to simulate the core concrete. The parameters in this model are set as follows: dilatancy angle $\psi=30^{\circ}$, flow potential offset $\varepsilon=0.1$, ultimate strength ratio of biaxial compression to uniaxial compression $\sigma_{b 0} / \sigma_{c 0}=1.16$, invariant stress ratio $K_{c}=0.667$, viscosity coefficient $\eta=0.005$.

The Guo Zhenhai curve (Guo, 2004) is used for the stress-strain relationship of the concrete, as shown in Fig. 2.

The plastic damage constitutive model of the concrete is shown in Fig. 3. The relationship between the plastic damage parameters $\left(d_{t}, d_{c}\right)$ of the concrete and the stress and strain in Fig. 3 are as follows:

- compression

$$
d_{c}=1-\frac{\sigma E_{0}^{-1}}{\varepsilon_{c}^{p l}\left(1 / b_{c}-1\right)+\sigma E_{0}^{-1}}
$$


(a)

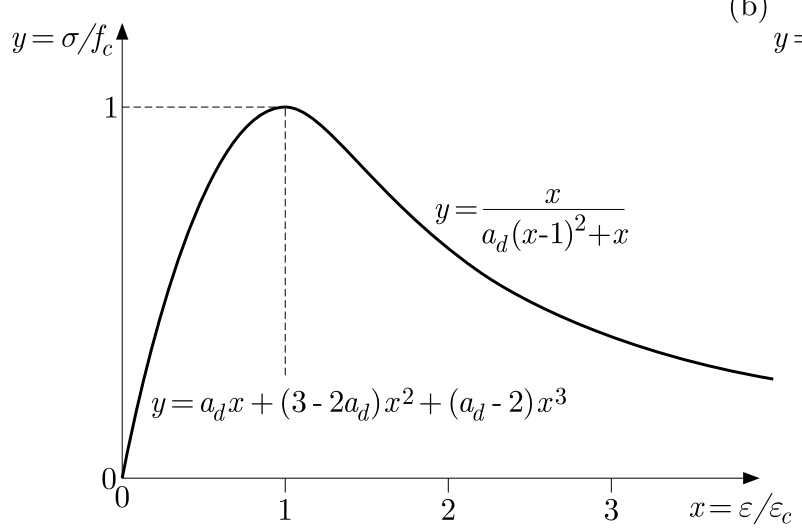

(b)

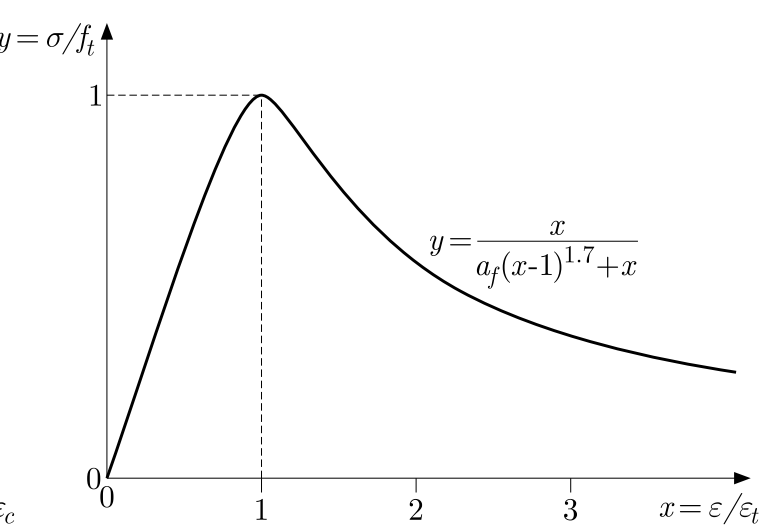

Fig. 2. Uniaxial stress-strain relationship. Stress-strain curve of the concrete under uniaxial: (a) compression, (b) tension

- tension

$$
d_{t}=1-\frac{\sigma E_{0}^{-1}}{\varepsilon_{t}^{p l}\left(1 / b_{t}-1\right)+\sigma E_{0}^{-1}}
$$

where: $b_{c}=\varepsilon_{c}^{p l} / \varepsilon_{c}^{i n}$, i.e., the ratio coefficient of compressed plastic strain to inelastic strain; $b_{t}=\varepsilon_{t}^{p l} / \varepsilon_{t}^{i n}$, i.e., the ratio coefficient of tensile plastic strain to cracking strain. It is suggested in the reference (Zhang and Liu, 2011) that the values of $b_{c}$ and $b_{t}$ are 0.7 and 0.1 , respectively.

(a)

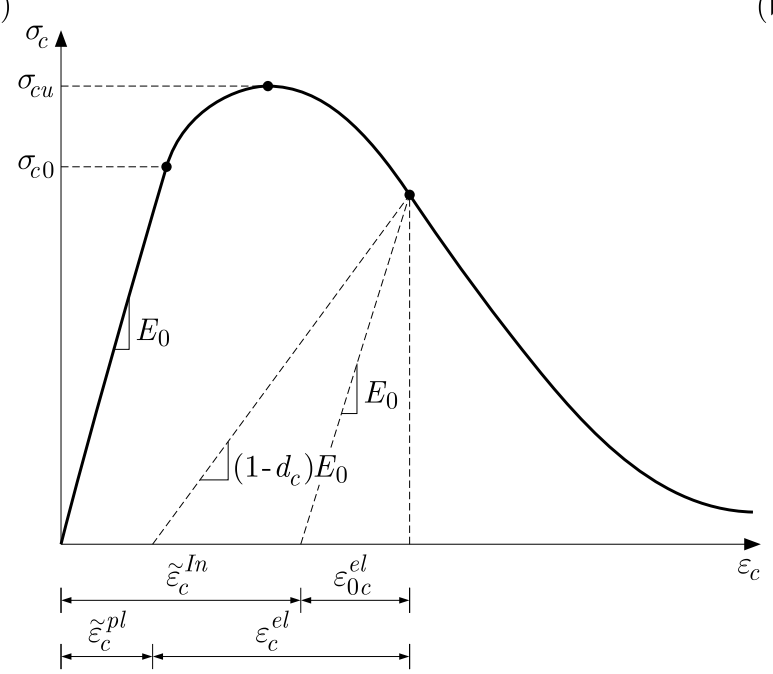

(b)

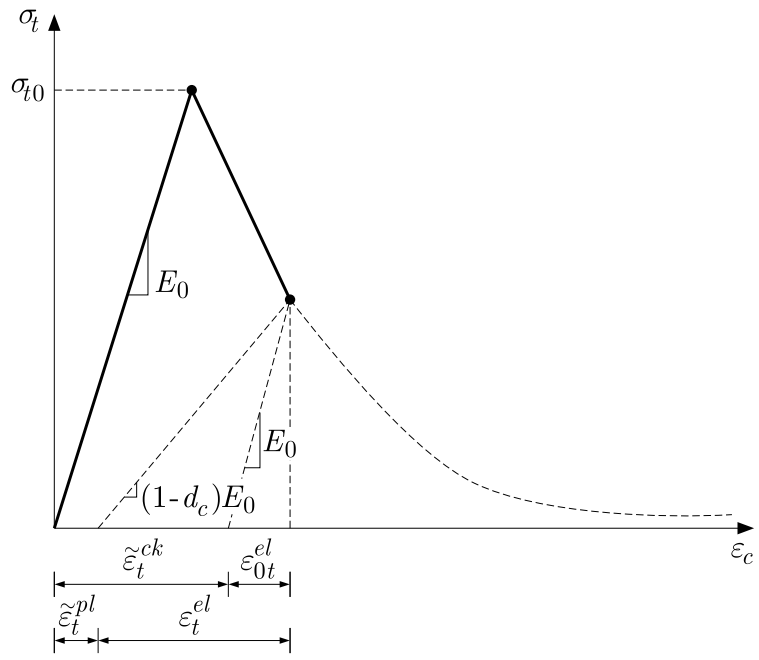

Fig. 3. Plastic damage constitutive model under: (a) compression, (b) tension

The local cracking of concrete may affect the continuity of stress wave transmission. The damage of concrete is not considered here to simplify the stress wave effect on the dynamic response. The following examples all belong to the low-velocity impact in order to focus the main point on the dynamic characteristic of the column. The effect of strain rate of the material is ignored temporarily.

\subsection{Simulation of interface contact between steel tube and core concrete}

The common node is used to simulate the interface contact between the steel tube and core concrete. 


\subsection{Geometric model}

The geometric and material parameters of the examples used in this paper are shown in Table 1. $P$ in the table is the first-order eigenvalue obtained by buckle calculation of the corresponding finite element model. In the study on the impact load, the buckling of the member is not considered. Thus, the $X$ and $Y$ directional displacements are restrained, and only the axial displacement of the top of the member is released. The dynamic explicit calculation module (Dynamic, Explicit) of ABAQUS is used for the finite element calculation.

Table 1. Calculation parameters of the concrete filled steel tubular column under a rigid-body impact

\begin{tabular}{|c|c|c|c|c|c|c|c|c|c|}
\hline $\begin{array}{c}\text { Serial } \\
\text { number }\end{array}$ & Number & $\begin{array}{c}D \times t \times L \\
{[\mathrm{~mm} \times \mathrm{mm} \times \mathrm{mm}]}\end{array}$ & $\theta$ & $L / i$ & $\begin{array}{c}E_{s} \\
{[\mathrm{MPa}]}\end{array}$ & $\begin{array}{c}f_{s} \\
{[\mathrm{MPa}]}\end{array}$ & $\begin{array}{c}E_{c} \\
{[\mathrm{MPa}]}\end{array}$ & $\begin{array}{c}f_{c t} \\
{[\mathrm{MPa}]}\end{array}$ & $\begin{array}{c}P \\
{[\mathrm{kN}]}\end{array}$ \\
\hline \hline 1 & GL1G1S1 & $108 \times 4 \times 5400$ & 2.09 & 200 & 205000 & 345.8 & 32017 & 36.3 & 162.052 \\
\hline 2 & GL1G1S2 & $108 \times 4 \times 5400$ & 1.23 & 200 & 205000 & 345.8 & 42100 & 60 & 177.534 \\
\hline 3 & GL1G1S3 & $108 \times 4 \times 5400$ & 0.92 & 200 & 205000 & 345.8 & 47200 & 76.8 & 185.345 \\
\hline 4 & GL1G2S1 & $108 \times 3 \times 5400$ & 1.55 & 203.8 & 205000 & 345.8 & 32017 & 36.3 & 132.136 \\
\hline 5 & GL1G3S1 & $108 \times 2 \times 5400$ & 1.02 & 207.7 & 205000 & 345.8 & 32017 & 36.3 & 103.304 \\
\hline
\end{tabular}

\subsection{Loading mode}

A circular shell with radius of $0.1 \mathrm{~m}$ is established as a rigid-body to impact the member. The rigid-body element is a 4-node bilinear rigid quadrilateral element (R3D4), and the rigid-body mass $\left(m_{r}\right)$ and initial velocity $\left(v_{r 0}\right)$ are given. The surface to surface contact is set up between the rigid-body and the top surface of the concrete filled steel tubular column, which means that the normal direction is hard contact and the tangential direction is no friction. The normal contact force of the contact surface is extracted as the impact load. The finite element model is shown in Fig. 4.

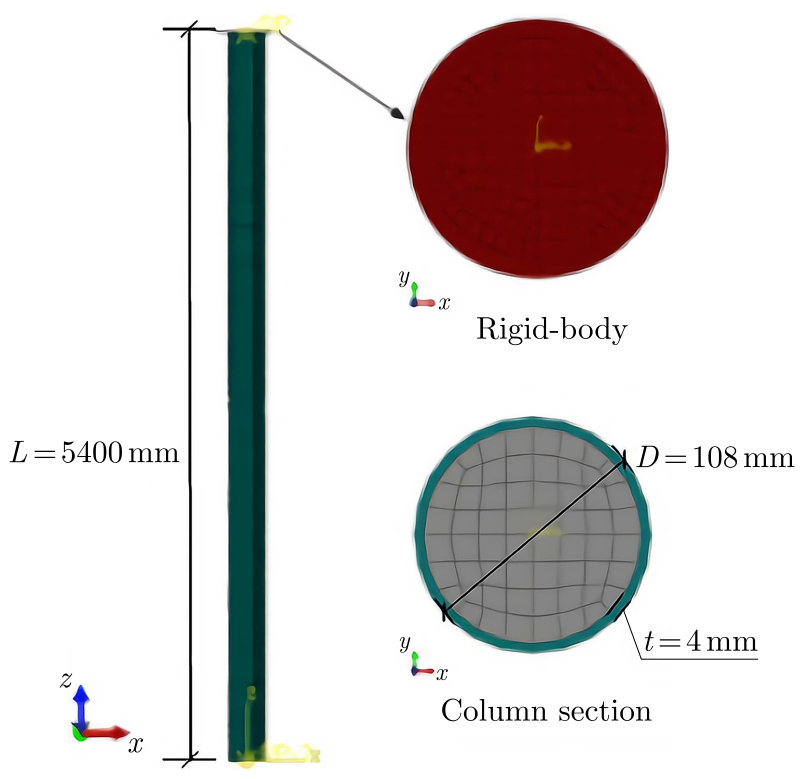

Fig. 4. Finite element model of the concrete filled steel tubular column under rigid-body impact 


\section{Characteristics of impact load}

This Section takes the member GL1G1S1 as the research object, and the influence of the mass $\left(m_{r}\right)$ and impact velocity $\left(v_{r 0}\right)$ of the rigid-body on the impact load is analyzed by changing these factors. The relationship between the time history curve of the impact load and the impact rigid-body mass at different impact velocities is featured in Fig. 5 and illustrated as follows. In the case of the same impact velocity, the early rising sections of time history curves of the impact load almost coincide. When the impact velocity is smaller, the time history curve of the impact load rises in a ladder shape obviously, and the platform segment is shorter, as shown in Figs. 5a, 5b and 5c. When the impact velocity is larger, the time history curve rises to a certain value at the very beginning of the impact. After the impact load is maintained at this value for a while, the curve begins to rise in the ladder shape, and the platform segment is longer, as shown in Figs. 5d and 5e. When the impact velocity is constant, the initial contact force between the rigid-body and the member, i.e., the first platform load value, is determined and has nothing to do with the impact mass. However, what the value of the impact load can rise to finally depends on the impact mass. The maximum value and duration of the impact load increase with an increase of the impact mass.

(a)

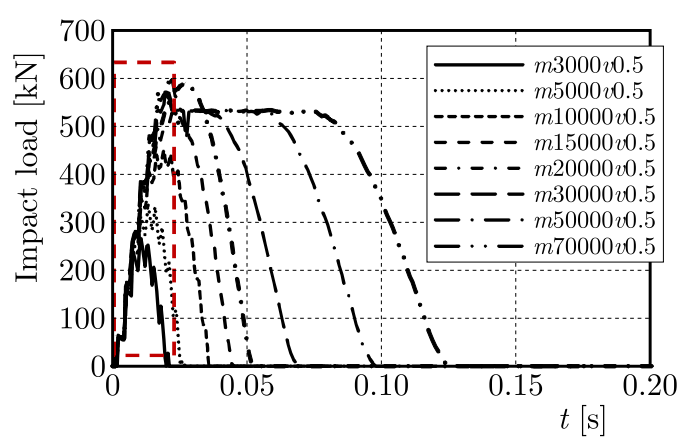

(c)

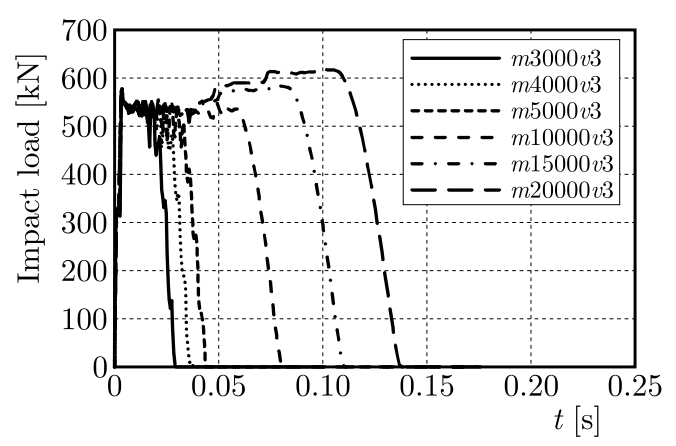

(b)

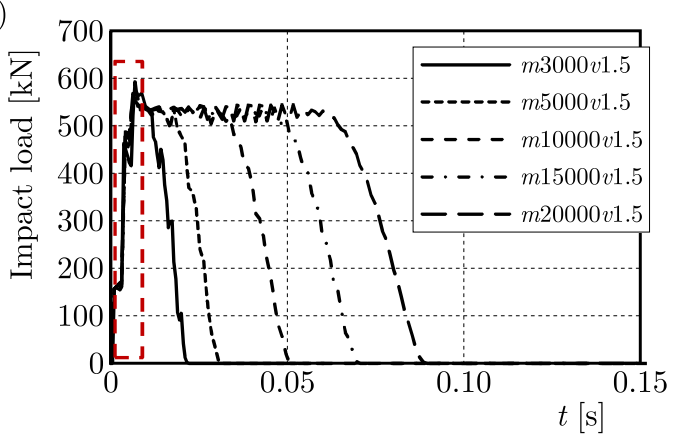

(d)

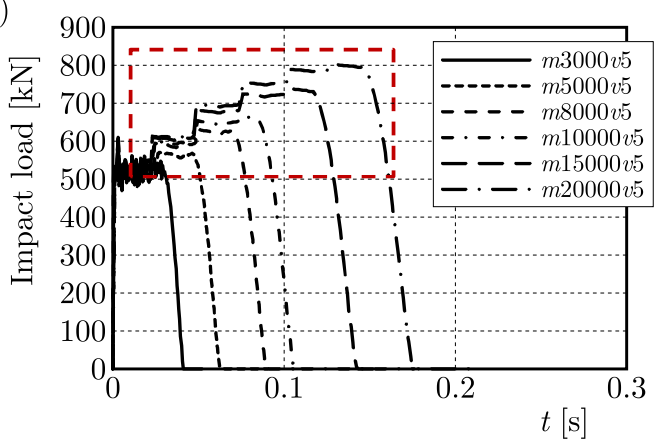

(e)

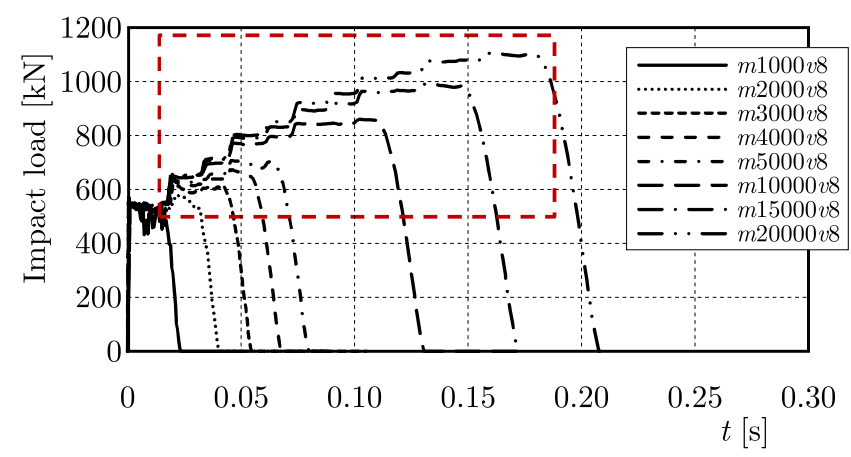

Fig. 5. Relationship between the impact load and the impact rigid-body mass $\left(m_{r}\right)$ (here m3000v0.5 represents $m_{r}=3000 \mathrm{~kg}$ and $v_{r 0}=0.5$ in the legend, the same below): (a) $v_{r 0}=0.5 \mathrm{~m} / \mathrm{s}$,

(b) $v_{r 0}=1.5 \mathrm{~m} / \mathrm{s}$, (c) $v_{r 0}=3 \mathrm{~m} / \mathrm{s}$, (d) $v_{r 0}=5 \mathrm{~m} / \mathrm{s}$, (e) $v_{r 0}=8 \mathrm{~m} / \mathrm{s}$ 
According to duration of the platform segment for the ladder form rise at the beginning of the impact shown in the red dotted box in Figs. 5a and 5b as well as that in the later stage of the impact as shown in the red dotted box in Figs. 5d and 5e, it is roughly judged that the short-term ladder form rise at the beginning of the impact is the load rise caused by the transmission of the elastic wave in the member, while the rise in the later stage of the impact is the load rise led by the transmission of the plastic wave in the member.

It is seen from the above calculation results that the form of time history curve of the impact load mainly depends on the impact rigid-body velocity. In the reference (Wang et al., 2017), the calculation method for the impact load of the elastic member under an axial rigid-body impact is proposed. The impact load at the beginning of the rigid-body impact $\left(F_{c}\right)$ can be calculated according to the following formula

$$
F_{c}=\rho A c_{0} v_{r 0}
$$

where $\rho$ is material density; $A$ is cross-sectional area; $c_{0}$ is elastic wave velocity; $v_{r 0}$ is impact velocity of the rigid-body.

By observing the formula, it is found that the impact load value at the initial impact contact is only related to the impact velocity of the rigid-body, but not to the mass of the rigid-body, which is consistent with the previous analysis in this Section. The formula is transformed into the initial impact load formula of the concrete filled steel tubular column without considering material nonlinearity, as shown below

$$
F_{c}=\left(\rho_{s} A_{s} c_{s 0}+\rho_{c} A_{c} c_{c 0}\right) v_{r 0}
$$

where $\rho_{s}$ and $\rho_{c}$ are material density of the steel tube and concrete, respectively; $A_{s}$ and $A_{c}$ are cross-section area of steel tube and concrete of the member, respectively; $c_{s 0}$ and $c_{c 0}$ are elastic wave velocity of the steel tube and concrete, respectively.

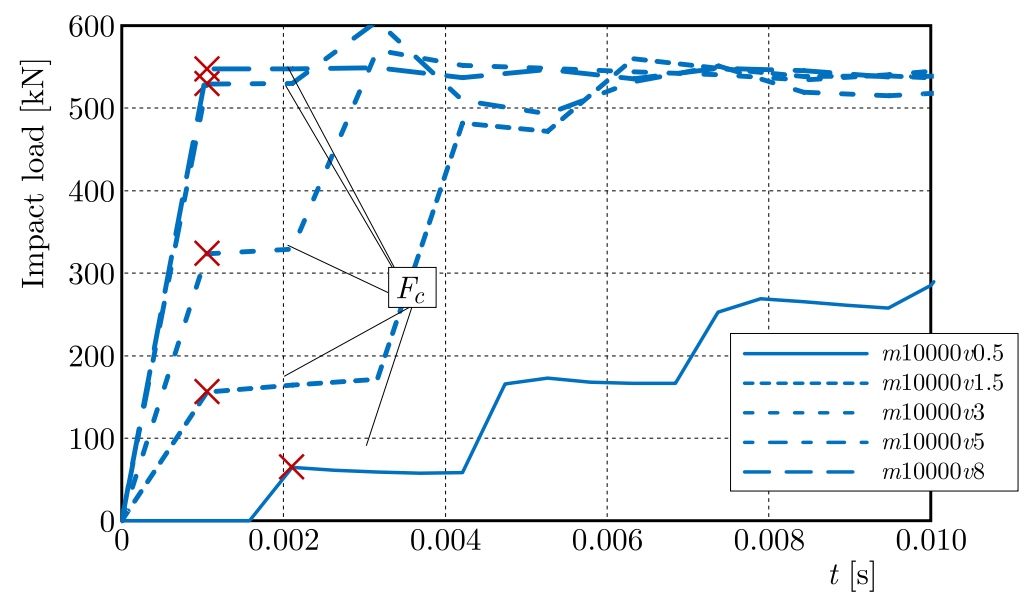

Fig. 6. $F_{c}$ value calculated by the finite element method

The impact load value at the initial impact contact calculated previously in this Section (the determination method is shown in Fig. 6) is compared with the impact load value calculated according to Eq. (3.2), as shown in Fig. 7. For convenience, the data points are classified according to the impact velocity and example number. There are at least three valid data points in each type example basically coincident in Fig. 7 , which indicates that the value of $F_{c}$ calculated by the finite element method is mainly related to the impact velocity of the rigid-body, but not to the mass of the rigid-body. Except for the data points in the red circle, most of the data points fall near the line " $F_{c}$ calculated by the finite element method $=F_{c}$ calculated by the formula". It is revealed that the initial impact load value of these examples can be accurately predicted 


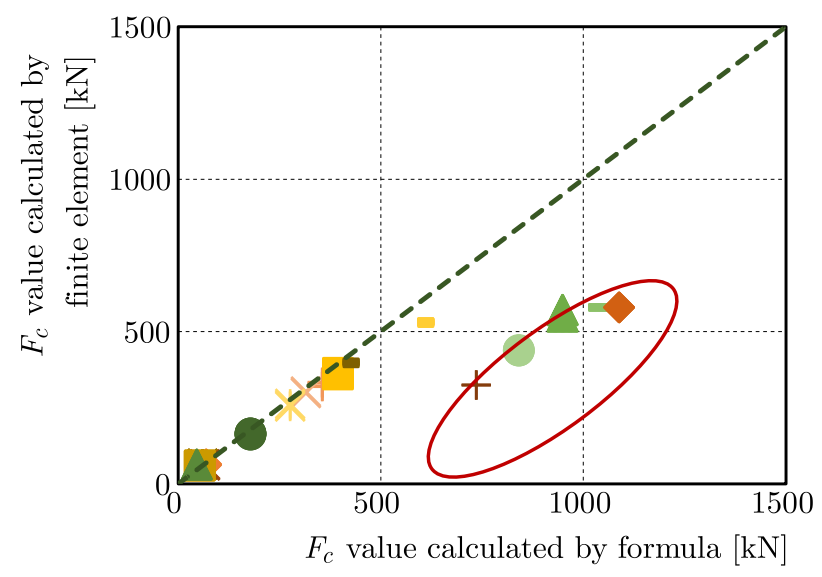

* v0.5: GL1G1S1

v1.5: GL1G1S1

+ v3: GL1G1S1

- v5: GL1G1S1

- v8: GL1G1S1

$\times v 0.5:$ GL1G1S2

$\checkmark v 0.5:$ GL1G1S2

v3: GL1G1S2

- v3: GL1G1S3

- v8: GL1G1S2

- v8: GL1G1S3

v0.5: GL1G2S1

\ v0.5: GL1G3S1

×3: GL1G2S1

v3: GL1G3S1

v8: GL1G2S1

Fig. 7. Comparison of $F_{c}$ value calculated by the finite element method and $F_{c}$ value calculated by the formula (here $v=v_{r 0}$ in the legend)

by Eq. (3.2). In contrast, the common ground of the corresponding examples of the data points in the red circle is that the impact velocity is relatively larger, and $F_{c}$ calculated by the finite element method is obviously smaller than that calculated according to Eq. (3.2). This suggests that when the rigid-body has a larger impact velocity, the concrete filled steel tubular column will enter into plasticity at the beginning of the impact, and the formula for the elastic member is not applicable in such conditions.

\section{The change of stress and strain of the concrete filled steel tubular column under rigid-body impact}

According to the discussion on the impact load in the previous Section, the form of the impact load varies with the change of initial velocity of the rigid-body. Consequently, the axial stress and strain characteristics of the concrete filled steel tubular column under the rigid-body impact need to be debated based on the initial velocity of the rigid-body.

Taking the initial velocity of the rigid-body $v_{r 0}=0.5 \mathrm{~m} / \mathrm{s}, 1.5 \mathrm{~m} / \mathrm{s}, 3 \mathrm{~m} / \mathrm{s}, 5 \mathrm{~m} / \mathrm{s}, 8 \mathrm{~m} / \mathrm{s}$ as examples, the axial fluctuation of the member GL1G1S1 under the rigid-body impact is explored. The impact loads for all examples in this Section are listed in Section 2. In the following, the axial stress and strain of the member under the impact of the rigid-body with different velocities will be discussed.

$\underline{v_{r 0}=0.5 \mathrm{~m} / \mathrm{s}}$

The time history curves of axial stress and axial strain at positions $A, B$ and $C$ shown in Fig. 8 are extracted for analysis. The stress and strain extraction position of the core concrete is located at the centroid of the circular section. Figure 9 plots the time history curve of axial stress and the time history curve of axial strain of the member under this condition.

\begin{tabular}{|c|c|c|c|}
\hline$\square C$ & $\nabla$ & & $\bar{A}$ \\
\hline $0.1 L$ & $0.4 L$ & $0.4 L$ & $0.1 L$ \\
\hline
\end{tabular}

Fig. 8. Schematic diagram of the axial stress extraction point

By combining Fig. 9 and Fig. 5a, it is found that the axial stress and strain of the member have the same rising and falling trend with the impact load at the beginning of the impact. Furthermore, it is seen that in the case of different impact rigid-body mass, the axial stress and 
strain of the members are different when the impact load is reduced to zero. When $m_{r}=10000 \mathrm{~kg}$ and $m_{r}=30000 \mathrm{~kg}$, the axial strain of the member can be restored to 0 after the end of the impact, which shows that the member does not produce visible plastic deformation under the impact, and the elastic strain is recoverable, and the axial stress decreases to near 0 after the end of the impact. When the impact rigid-body mass is larger, such as $m_{r}=50000 \mathrm{~kg}$ and $m_{r}=70000 \mathrm{~kg}$, the strain of the top part of the member cannot be restored to 0 after the end of the impact, which indicates that the impact rigid-body has considerable initial energy, and this part of the member enters plastic deformation with transmission of the stress wave in the member. The steel tube and the core concrete need to meet the deformation compatibility condition, but the elastic deformation recovery of the steel tube is less than that of the core concrete. Therefore, after the end of the impact, the steel tube is in axial tension, while the core concrete is under axial compression.

(a)

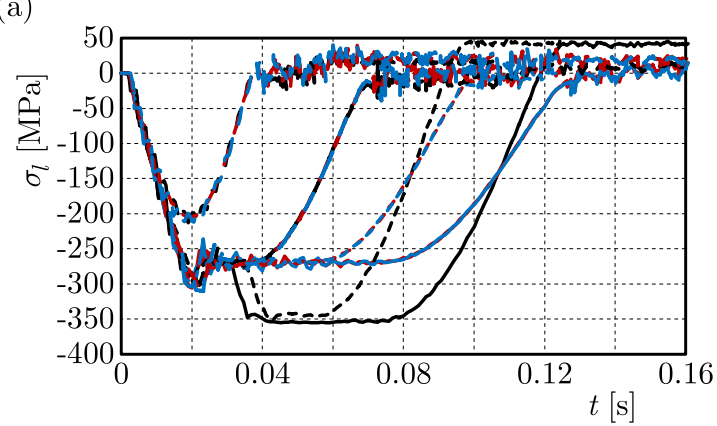

(c)

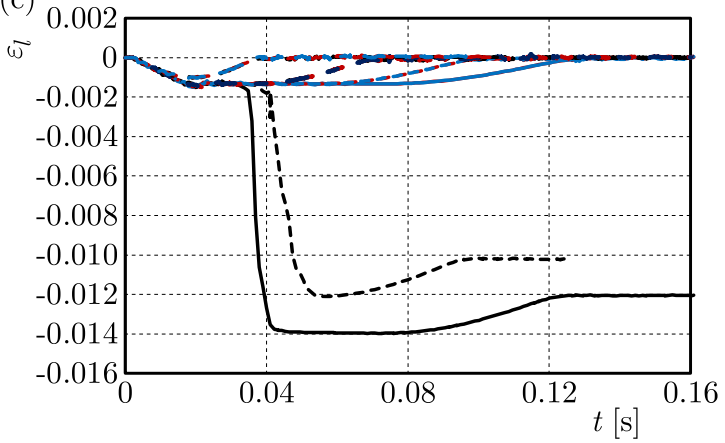

(b)

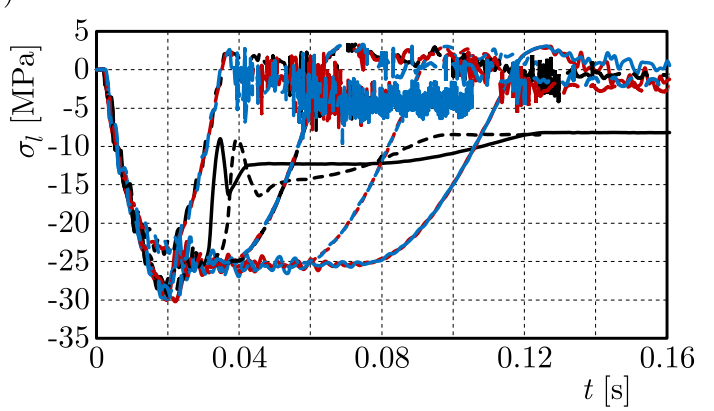

(d)

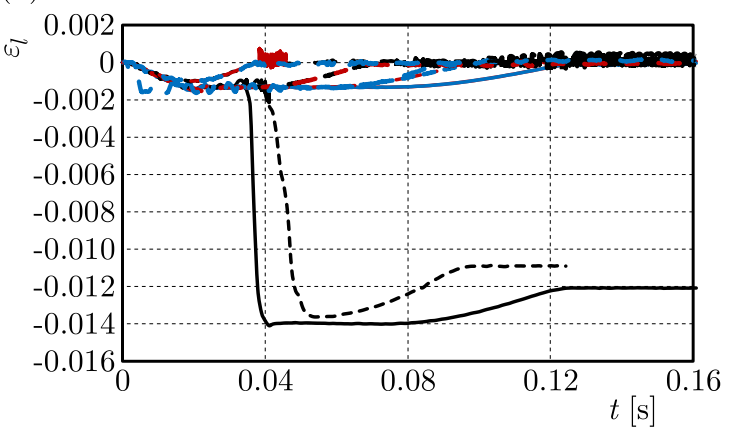

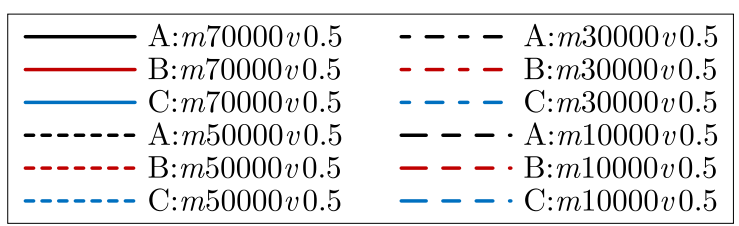

Fig. 9. Time history curves of axial stress and axial strain the member when $v_{r 0}=0.5 \mathrm{~m} / \mathrm{s}$ (here Figs. (a), (b), (c) and (d) share the legend of Fig. (d), where $m=m_{r}, v=v_{r 0}$ ). (a), (c) Time history curve of axial stress of the steel tube, (b), (d) time history curve of axial stress of the core concrete

$v_{r 0}=1.5 \mathrm{~m} / \mathrm{s}$

Figure 10 illustrates the time history curve of axial stress and the time history curve of axial strain of the member when $v_{r 0}=1.5 \mathrm{~m} / \mathrm{s}$. The variation characteristics of axial stress and strain with time in Fig. 10 are similar to those in Fig. 9. It is observed that in the condition of the same rigid-body mass, the strain of the member under the impact of the rigid-body with the higher initial velocity is larger. For example, under the impact of the rigid-body with $m_{r}=10000 \mathrm{~kg}$, when $v_{r 0}=1.5 \mathrm{~m} / \mathrm{s}$, the part near the impact end gets into plasticity, in contrast 
when $v_{r 0}=0.5 \mathrm{~m} / \mathrm{s}$, the axial deformation of the member basically returns to 0 after the end of the impact.

(a)

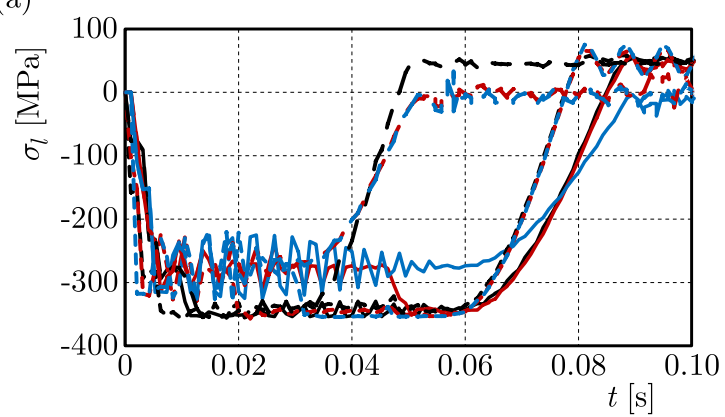

(c)

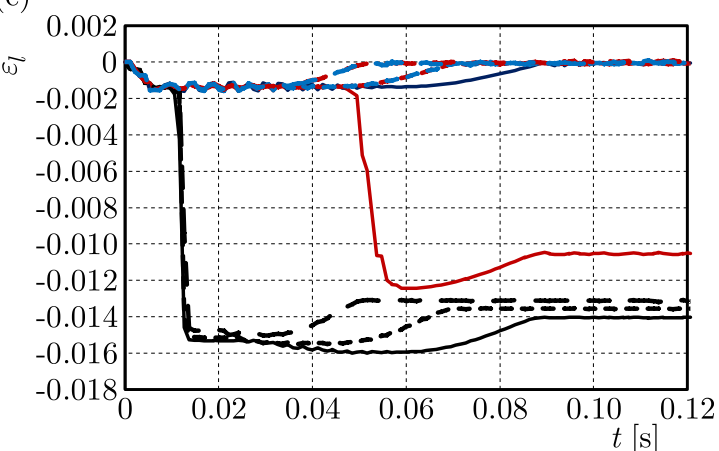

(b)

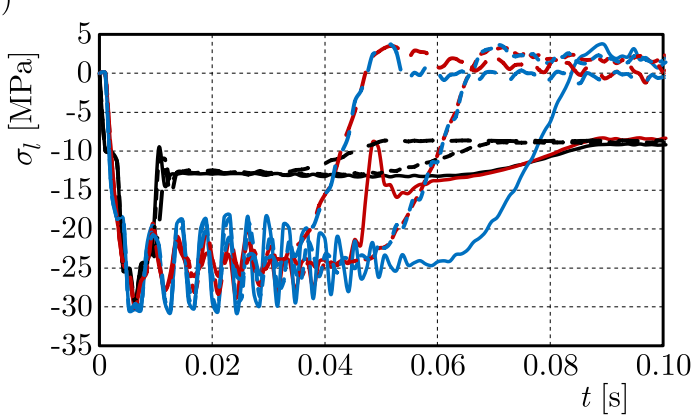

(d)

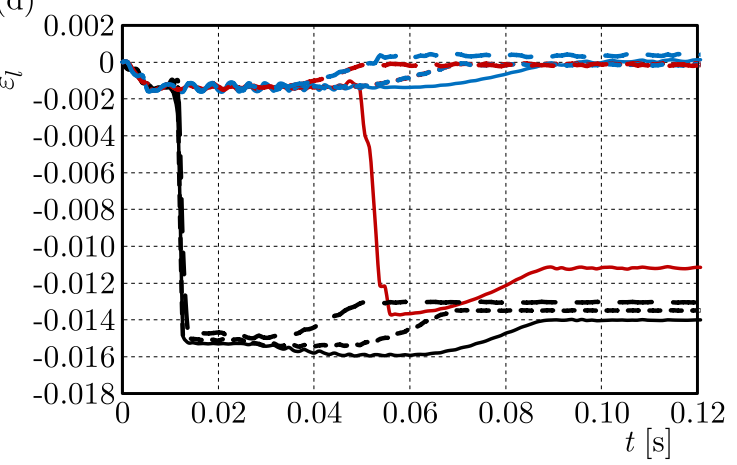

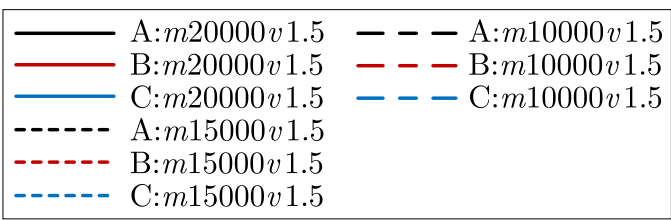

Fig. 10. Time history curves of axial stress and axial strain of the member when $v_{r 0}=1.5 \mathrm{~m} / \mathrm{s}$ (here Figs. (a), (b), (c) and (d) share the legend of Fig. (d), where $m=m_{r}, v=v_{r 0}$ ). (a), (c) Time history curve of axial stress of the steel tube, (b), (d) time history curve of axial stress of the core concrete

\section{$\underline{v_{r 0}=3 \mathrm{~m} / \mathrm{s}}$}

The time history curve of axial stress and the time history curve of axial strain of the member when $v_{r 0}=3 \mathrm{~m} / \mathrm{s}$ are featured in Fig. 11. Combined with the time history curve of the impact load shown in Fig. 5c, a change of axial stress and strain with time is observed. The axial strain and stress still increase with an increase of the impact load and decrease with a decrease of the impact load. However, owing to the higher impact velocity of the rigid-body, the strain level of the member under the impact is higher than that of the smaller impact velocity in the case of the same rigid-body mass. For example, under the impact of the rigid-body with $m_{r}=1000 \mathrm{~kg}$, when $v_{r 0}=3 \mathrm{~m} / \mathrm{s}$, the whole member enters plastic deformation, when $v_{r 0}=1.5 \mathrm{~m} / \mathrm{s}$, only a part near the impact end goes into plastic deformation.

$>\underline{v_{r 0}=5 \mathrm{~m} / \mathrm{s}}$

Figure 12 plots the time history curve of axial stress and the time history curve of axial strain of the member when $v_{r 0}=5 \mathrm{~m} / \mathrm{s}$. Combined with Fig. $5 \mathrm{~d}$, it is still found that the axial strain and stress of the member increase with the increase of the impact load and decrease with the decrease of the impact load. When the initial velocity of the rigid-body is larger, the axial strain caused by the impact of the rigid-body with the same mass is also larger. For example, under 


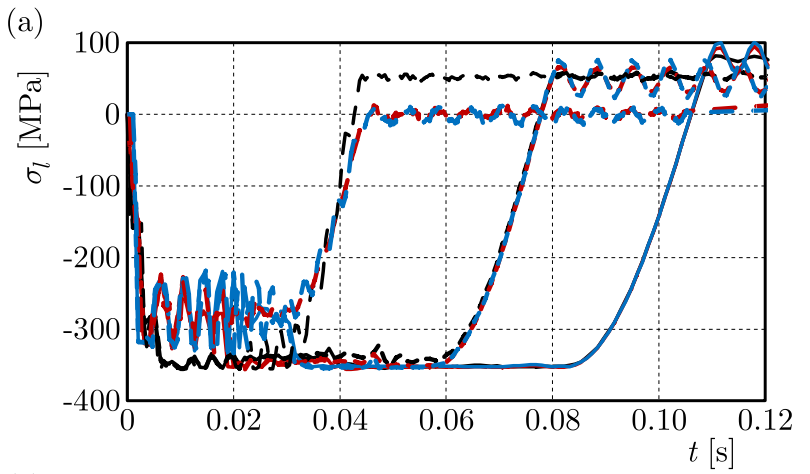

(c)

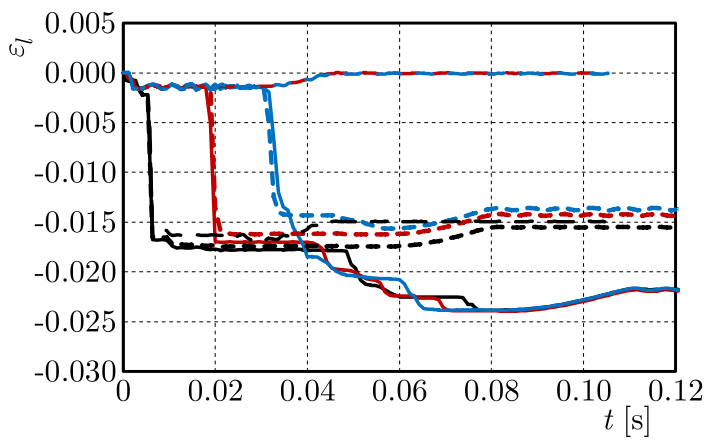

(b)

(d)
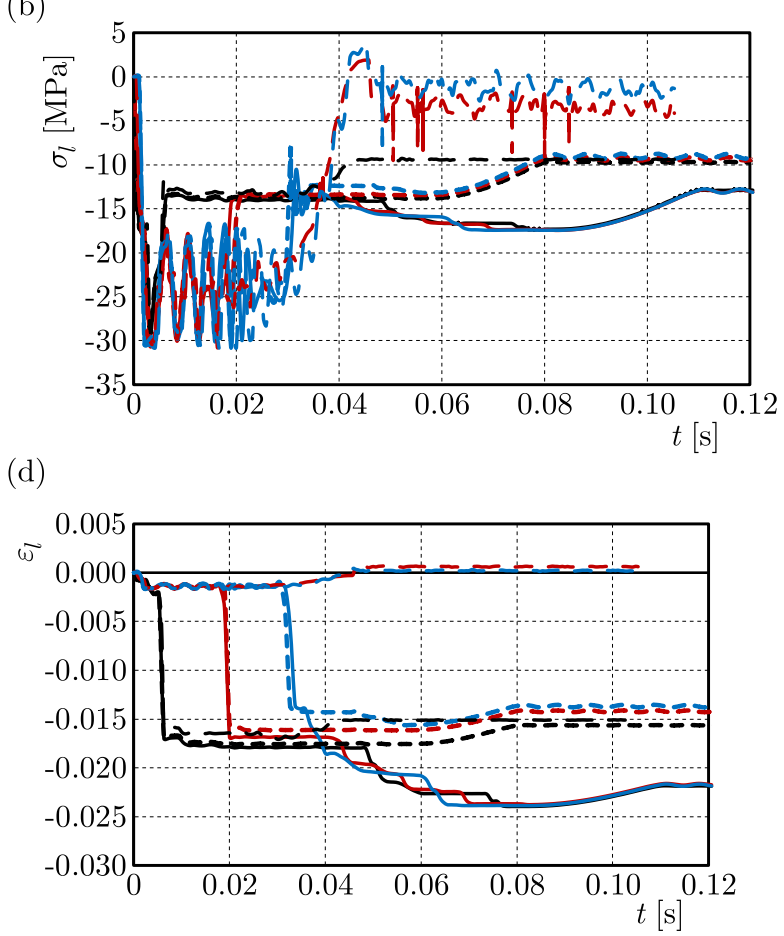

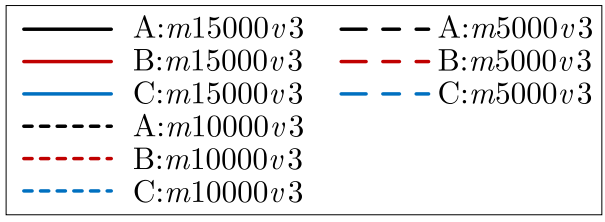

Fig. 11. Time history curves of axial stress and axial strain of the member when $v_{r 0}=3 \mathrm{~m} / \mathrm{s}$ (here Figs. (a), (b), (c) and (d) share the legend of Fig, (d), where $m=m_{r}, v=v_{r 0}$ ). (a), (c) Time history curve of axial stress of the steel tube, (b), (d) time history curve of axial stress of the core concrete

the impact of the rigid-body with $m_{r}=1000 \mathrm{~kg}$, the axial strain is larger when $v_{r 0}=5 \mathrm{~m} / \mathrm{s}$ than $v_{r 0}=3 \mathrm{~m} / \mathrm{s}$. The order of each point entering plasticity in the example shown in Fig. 12 is point $C$, point $B$, and point $A$. The bottom end of the member enters into plastic deformation first, which means that the plastic deformation is first created by reflection of the elastic wave reaching the bottom of the member. Different from this, Fig. 11 shows that the order of each point entering plasticity is: point $A$, point $B$, and point $C$. In other words, the part near the impact end enters plasticity first, which indicates that the plastic deformation is first produced by the impact.

$>\underline{v_{r 0}=8 \mathrm{~m} / \mathrm{s}}$

Figure 13 depicts the time history curve of axial stress and the time history curve of axial strain of the member when $v_{r 0}=8 \mathrm{~m} / \mathrm{s}$. Combined with Fig. $5 \mathrm{e}$, the variation trend of axial strain and stress with the impact load is consistent with the previous analysis. However, as shown in Fig. 13, the order of each point entering plasticity is: point $A$, point $C$, and point $B$. Once the rigid-body contacts the member initially, the top of the member will enter plastic deformation. And then, the plastic deformation at the bottom of the member is caused by reflection of the elastic wave transmitted to the bottom at a fast velocity. Point $B$ is located in the middle of the member where the plastic wave velocity is slower, so point $B$ is the last one getting into plasticity. If the impact rigid-body has greater kinetic energy, the member needs to absorb more energy, the level of stress and strain is relatively higher, and the residual strain after the end of the impact is also larger. 
(a)

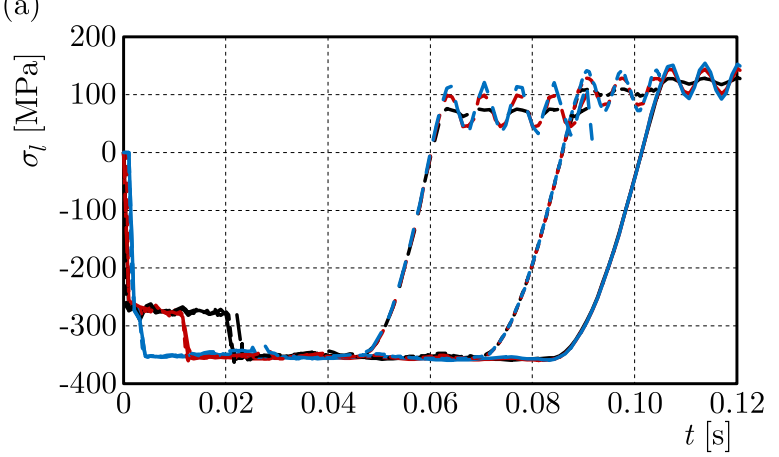

(c)

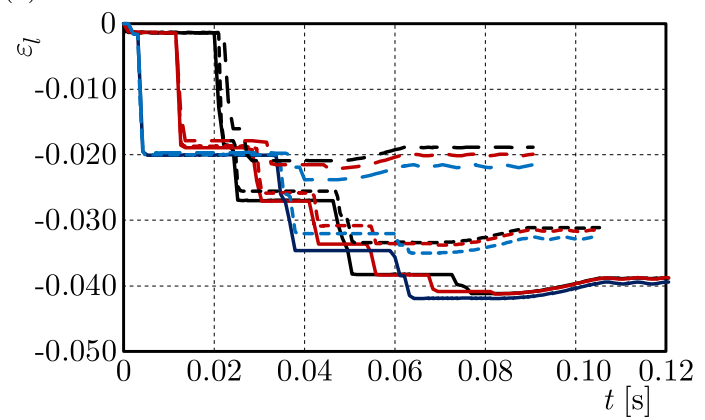

(b)

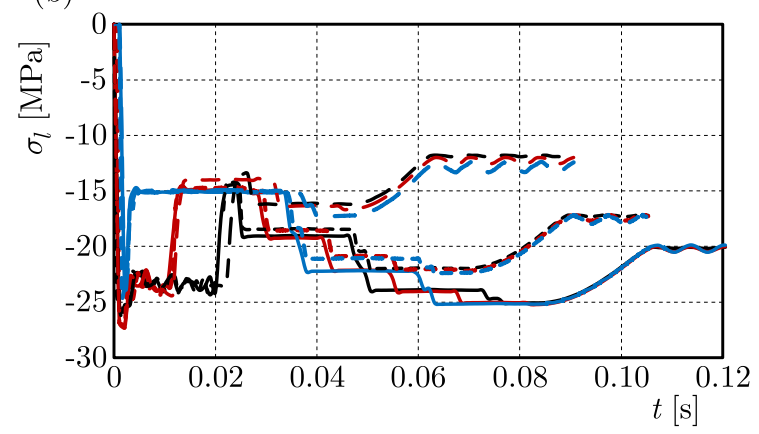

(d)

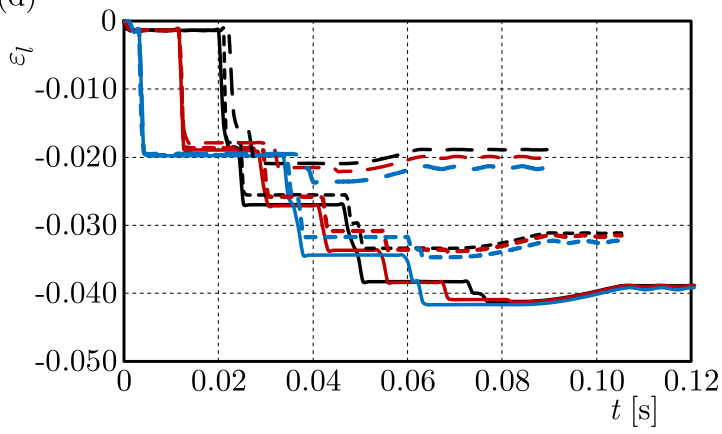

$$
\begin{array}{lll}
\hline & \text { A: } m 10000 v 5 \text { - }-\mathrm{A}: m 5000 v 5 \\
\text { B: } m 10000 v 5 \text { - } & \text { B: } m 5000 v 5 \\
\hline & \text { C: } m 10000 v 5 \text { - - C: } m 5000 v 5 \\
\hdashline-\cdots & \text { A: } m 8000 v 5 \\
-\cdots- & \text { B: } m 8000 v 5 \\
-\cdots & \text { C: } m 8000 v 5
\end{array}
$$

Fig. 12. Time history curves of axial stress and axial strain of the member when $v_{r 0}=5 \mathrm{~m} / \mathrm{s}$ (here Figs. (a), (b), (c) and (d) share the legend of Fig. (d), where $m=m_{r}, v=v_{r 0}$ ). (a), (c) Time history curve of axial stress of the steel tube, (b), (d) time history curve of axial stress of the core concrete

\section{Conclusion}

In this paper, the dynamic response of concrete filled steel tubular long columns with a length diameter ratio $L / D$ of 50 under a rigid-body impact is discussed by a numerical simulation method. The following conclusions can be drawn:

- The form of the impact load on a concrete filled steel tubular column under the axial impact of a rigid-body was discussed. It is found that the form of the impact load is related to the impact velocity but not the mass of the rigid-body. The impact velocity and mass of the rigid-body jointly determine the duration of the impact load. The formula $F_{c}=\left(\rho_{s} A_{s} c_{s 0}+\rho_{c} A_{c} c_{c 0}\right) v_{0}$ can be used to calculate the impact load value at the initial impact contact, and the relationship between $F_{c}$ and $F_{C S}=f_{y} A_{s}+f_{c} A_{c}$ can roughly predict the form of the impact load.

- The change of axial stress and strain with time of the member under the rigid-body impact was studied. It is discovered that the variation trend of axial stress and strain with time is synchronous with that of the impact load. In particular, the variation characteristics of axial stress and strain with time are mainly related to the initial velocity of the rigid-body, and the values of axial stress and strain of the member under the impact have to do with the initial velocity and mass of the rigid-body. 
(a)

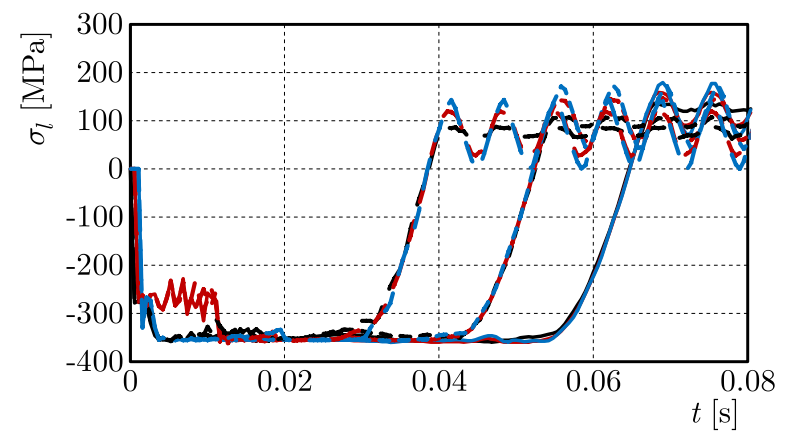

(c)

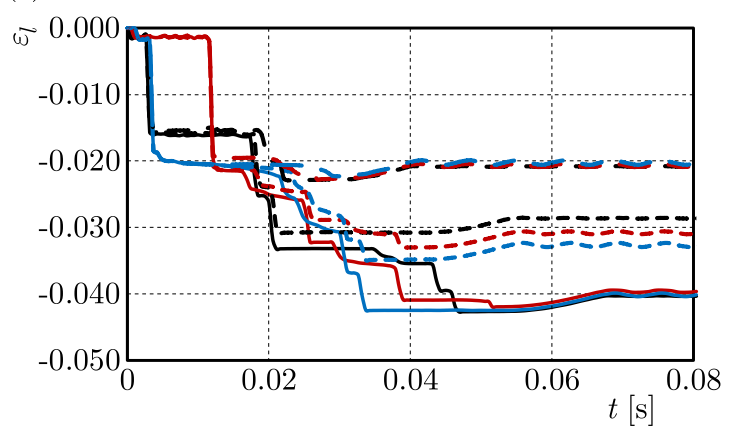

(b)

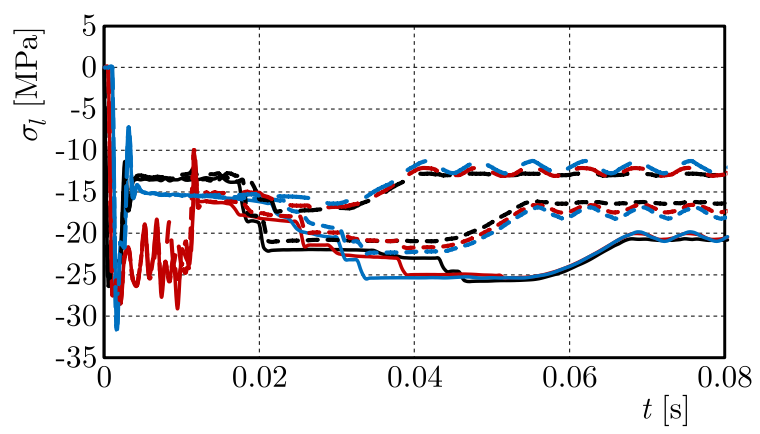

(d)

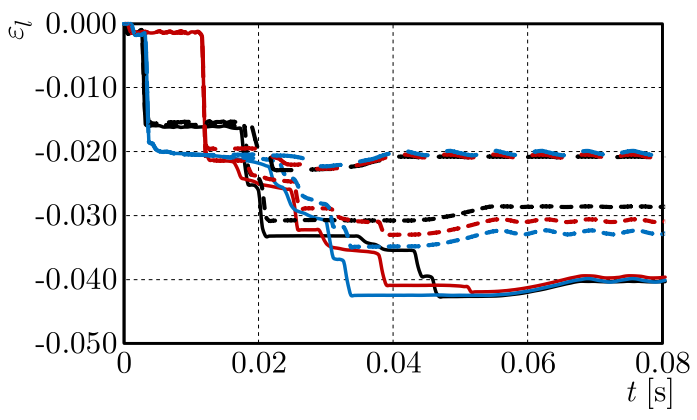

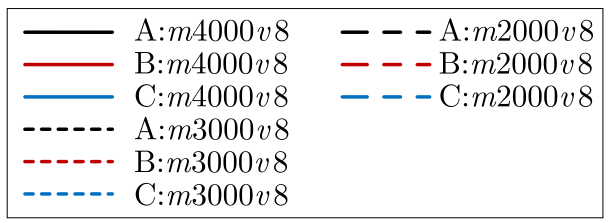

Fig. 13. Time history curves of axial stress and axial strain of the member when $v_{r 0}=5 \mathrm{~m} / \mathrm{s}$ (here Figs. (a), (b), (c) and (d) share the legend of Fig. (d), where $m=m_{r}, v=v_{r 0}$ ). (a), (c) Time history curve of axial stress of the steel tube, (b), (d) time history curve of axial stress of the core concrete

\section{Acknowledgment}

The research was supported by the National Natural Science Foundation of China (51279206).

\section{References}

1. Aghdamy S., Thambiratnam D.P., Dhanasekar M., Saiedi S., 2015, Computer analysis of impact behavior of concrete filled steel tube columns, Advances in Engineering Software, 89, 52-63

2. Demartino C., Wang X.Y., Xu J.J., Xiao Y., 2017, Dynamic response of concrete filled steel tube column under lateral impact load: experimental study and calculation method, China Civil Engineering Journal, 50, 12, 28-36

3. Guo Z.H., 2004, Strength and Constitutive Relation of Concrete: Principle and Application (in Chinese), Beijing, China Architecture and Building Press

4. Li Z., Li B.C., Li Y.G., 2006, The research of the dynamic property of steel tube-confined concrete short column under axial impact (in Chinese), Journal of Taiyuan University of Technology, 4, 4-6

5. Liu H.L., Ding X.M., 2007, Analytical solution of dynamic response of cast-in-situ concrete thinwall pipe piles under transient concentrated load with low strain (in Chinese), Chinese Journal of Geotechnical Engineering,11, 20-26

6. LiU H.L., Ding X.M., 2008, Propagation characteristics of transient waves in low strain integrity tests on cast-in-situ concrete thin-wall pipe piles (in Chinese), Chinese Journal of Geotechnical Engineering, 3, 111-116 
7. Mirmomeni M., Heidarpour A., Zhao X.L., Al-Mahaidi R., Packer J.A., 2017, Size-dependency of concrete-filled steel tubes subject to impact loading, International Journal of Impact Engineering, 100, 90-101

8. Prichard S.J., Perry S.H., 2000, The impact behaviour of sleeved concrete cylinders, Structural Engineer, 78, 17, 23-27

9. WANG H.Z., 2017, Analytical solution for stress waves of hollow concrete filled steel tubular piles subjected to axial impact (in Chinese), Engineering Mechanics, 34, 4, 106-112

10. WANG W.Q., Wu C.Q., Li J., LiU Z., LV Y., 2019, Behavior of ultra-high performance fiber-reinforced concrete (UHPFRC) filled steel tubular members under lateral impact loading, International Journal of Impact Engineering, 132, 1-24

11. YANG X.Q., YAng H., Zhang S.M., 2020, Transverse impact behavior of high-strength concrete filled normal-/high-strength square steel tube columns, International Journal of Impact Engineering, 139, 1-14

12. Zhang C., Xu X.Q., 2009, Test research of concrete-filled steel tube column under axial impact load (in Chinese), Journal of Nantong University (Natural Science Edition), 4, 59-63

13. Zhang Z.T., LiU Y.F., 2011, Concrete damaged plasticity model in ABAQUS (in Chinese), Building Structure, S2, 229-231

Manuscript received March 8, 2021; accepted for print May 17, 2021 